\title{
Editorial: Insights
}

\section{Stoyan Tanev, Editor-in-Chief, Gregory Sandstrom, Managing Editor}

Welcome to the December issue of the Technology Innovation Management Review. This issue consists of a mixture of "Insights".

The first paper is Sara Moqaddamerad's "Visioning Business Model Innovation for Emerging 5G Mobile Communications Networks". Her paper targets the intersection between strategic foresight and business model innovation, using 5G networks as a case study. It attempts to synthesize evidence of business model innovation (BMI) by emerging disruptive technologies as examples of how to use future-oriented "foresight" techniques. The research sought to uncover how to strategically integrate foresight into BMI processes in the context of the telecommunications industry, through a series of participant interviews and 2 company workshops. While speculative in orientation, the paper offers helpful advice in "visioning" business futures, especially for companies facing competition, when technology-driven innovation is available that could impact their business models.

Jahja Rrustemi and Nils S. Tuchschmid follow with "Facebook's Digital Currency Venture "Diem": the new Frontier ... or a Galaxy far, far away?" Their paper looks at the brief history of Facebook's new digital currency or token "Diem" and "Novi" wallet. The paper addresses how they are using distributed ledger (blockchain) technology to enable a permissioned network of users who may benefit from digital transactions with accessible products and services worldwide. The paper's main focus on the financial industry, local currencies, economic inclusion, and generally on tokenization, offers a suitable background for one of the first scholarly papers published on Diem. The authors note with caution and concern Facebook's history with the monetization of personal information, and that "[s] everal issues with Diem remain problematic that we believe have not yet been satisfactorily tackled" (pg. 27). At the same time, they "foresee profitability from using Diem tokens that can be investigated and developed" (pg. 28. The paper raises several difficult questions about this financial experiment, which may provoke tech entrepreneurs globally.

The next paper by Pınar Buyukbalci, Esin Ertemsir, and Zayneb Boukari looks at "Embracing Product Innovativeness in Technology Firms: The Impact of Management Model Principles". After first defining both "management model" and "product innovativeness" from the existing literature, the authors add to it by exploring the impact of management models on product innovativeness. They create and report on a questionnaire with 55 questions, focusing on the above defined terms. Their questionnaire targeted 723 companies located in science parks hosted by technical universities. The authors "assume that management model principles are manifested in product innovation processes and practices" (pg. 35) in coming up with three hypotheses that they develop in the paper. Overall, the paper aims "to help companies develop a better understanding of the role of management models in fostering product innovativeness" (pg. 42).

Finally, Rui Nuno Castro and João José Pinto Ferreira present "Project Portfolio Management in the Front-End of Innovation of Research Centers". Their study is based on an in-depth literature review of 170 papers in SCOPUS focussing on project portfolio management (PPM) and front-end of innovation (FEI), from which they identified 25 discussion threads based on 12 distinct concept groups. The authors used a theoretical tool by Pereira et al., 2020 called "Front-End of Innovation Integrative Ontology (FEI2O)" to assist in framing the discussion. Their inquiry aims to help research centers prioritize research project ideas, measure FEI success, and manage collaborative projects with industry.

The TIM Review currently has a Call for Papers on the website for Upcoming Themes with a special edition on "Aligning Multiple Stakeholder Value Propositions" (April 2021). For future issues, we invite general submissions of articles on technology entrepreneurship, innovation management, and other topics relevant to launching and scaling technology companies, and for solving practical business problems in emerging domains such as artificial intelligence and blockchain applications in business. Please contact us with potential article ideas and submissions, or proposals for future special issues.

\section{Stoyan Tanev Editor-in-Chief Gregory Sandstrom Managing Editor}

Citation: Tanev, S., \& Sandstrom, G. 2020. Editorial - Insights. Technology Innovation Management Review, 10(12): 3.

http://doi.org/10.22215/timreview/1409

(cc) BY

Keywords: business model innovation, strategic foresight, visioning, Diem, blockchain, digital currency, financial industry, product innovativeness, management models, project portfolio management, front-end of innovation, ideation, not-for-profits, research center 